ing interest, for example, outbreaks, TB, or antibioticresistant organisms. "New business" at each meeting should include a brief summary of surveillance data. Overly detailed reports of infection rates usually do not interest the full committee. One way to retain members' attention is to highlight a specific topic during each meeting. For example, infection control personnel can discuss changes in antibiotic susceptibility patterns of important nosocomial pathogens or can review rates of particular infections, such as Clostridium difficile colitis. If available, reports from the state or local health department may provide additional insight into trends seen within an institution.

Finally, you should discuss new policies or procedures and substantial revisions to current protocols. You should try to approve one new policy or procedure per meeting. However, do not schedule a policy for discussion until your team has reviewed the literature thoroughly and has sought the advice of clinical experts. When your team has synthesized all pertinent information, you should present the options to the committee. Concise handouts with excellent illustrations often will clarify your recommendations. Once the committee has heard and discussed all of the data, the members immediately should vote on the policy. We recommend that you deal with items requiring the committee's approval in a single meeting, because meetings easily bog down if debate drags out from month to month. The infection control team can prevent many of these impasses by working to gain the support of committee members before the meeting.

\section{REASSESSMENT}

The infection control committee should reassess its performance periodically. Infection control team members should list and evaluate their accomplishments and state their priorities. You should not be afraid to ask hard questions. Has the TB isolation policy reduced exposures? Have the rates of VRE bacteremia increased? Does your surveillance system identify surgical infections in patients undergoing surgery as outpatients? Has the committee passed 12 new or revised policies over the past 12 months? During this process, you also should eliminate policies and procedures that are inefficient or no longer necessary. If the infection control team critically assesses its priorities and performance, it can adapt to changes in the healthcare environment. Revitalized, it will be able to greet the new challenges with insight and energy.

\section{BIBLIOGRAPHY}

1. Ayliffe GA. Infection control in the United Kingdom. Chemotherapy 1988,34(6):536-540.

2. Brachman PS, Haley RW. Nosocomial infection control: role of the hospital administrator. Reviews of Infectious Diseases $1981 ; 3(4): 783-784$.

3. Haley RW. The 'hospital epidemiologist' in US hospitals, 19761977: a description of the head of the infection surveillance and control program. Infect Control 1980;1:21-32.

4. Shands JW Jr, Wenzel RP, Wolff SM, Eickhoff TC, Fields BN, Jackson GG. Hospital epidemiology and infection control: the changing role of the specialist in infectious diseases. $J$ Infect $D i$ is 1982;144:609-613.

5. Wenzel RP. Management principles and the infection-control committee. In: Wenzel RP, ed. Prevention and Control of Nosocomial Infections. 2nd ed. Baltimore, MD: Williams \& Wilkins; 1993:207-213.

\title{
Availability of Consensus Statement
}

\section{Edited by Gina Pugliese, RN, MS Medical News Editor}

Full text of the January 9-11, 1995, NIH consensus panel on this topic recently was distributed widely and currently is available from the
NIH Consensus Program Information Service, (800) 644-6627, or from the Office of Medical Applications of Research, NIH, Federal Bldg, Room 618, 7550 Wisconsin Ave, MSC9120, Bethesda, MD 20892-9120. (The panels' conclu- sions on the issues that were at hand are as follows: As well as testing for HIV 1 and 2 antibodies, HTLV I/II, and $\mathrm{HCV}$, continue testing for hepatitis B core antigen and syphilis and discontinue the use of the serum alanine aminotransferase test.) 